\title{
Comida de Coro: de Gracias,
}

\section{señor à Uzyna Uzona}

Food for the choir: from Gracias,

señor to Uzyna Uzona

\section{Luiz Fernando Ramos}

Luiz Fernando Ramos

Professor Titular do Departamento de Artes Cênicas da Escola de

Comunicações e Artes da Universidade de São Paulo

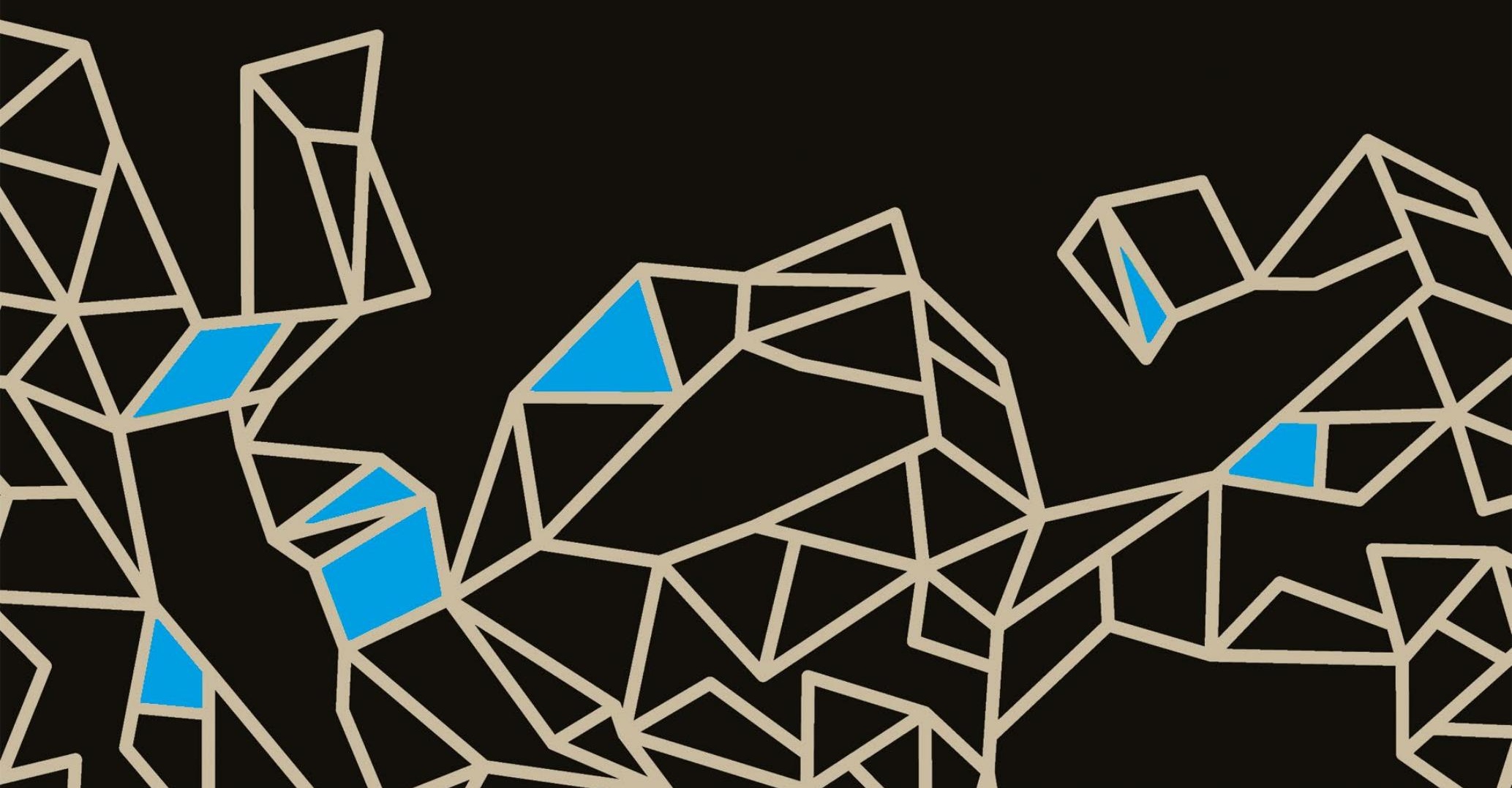




\section{Resumo}

Gracias, señor, o mítico espetáculo de 1971 do Teatro Oficina, sempre foi compreendido, na história do teatro brasileiro, como um ponto fora da curva que teria provocado uma profunda crise no grupo, levando ao seu desmanche. Este artigo recusa essa tese, projetando o espetáculo como a semente que germinará, duas décadas depois, na constituição e trajetória vitoriosa da Uzyna Uzona. Desencadeador do processo de radicalização política e estética (que alcançou seu ápice na revolução portuguesa de 1974) e implicou no desfazimento do coletivo original, Gracias, señor, sugere-se aqui, cria as fundações daquilo que foi produzido nos três últimos decênios. De fato, o atual Teatro Oficina Uzyna Uzona é a realização acabada da utopia que aquela experiência projetou e que décadas de maturação conseguiram engendrar.

Palavras-chave: Oficina, Uzyna Uzona, Coro, Gracias Señor, Revolução.

\section{Abstract}

Gracias, señor, the mythic Teatro Oficina's performance of 1971 was always understood in Brazilian theatre history as an atypical spectacle, which provoked a deep crisis in the group and led to its extinction. This article refuses this thesis and projects that performance as the seed that would constitute the victorious trajectory of Uzyna Uzona two decades latter. Trigger of a political and aesthetical radicalization process that reached its climax in the Portuguese revolution of 1974 and implied on the dismantling of the original collective, Gracias, señor, creates the foundations of what was produced in the last three decades. Actually, the present Teatro Oficina Uzyna Uzona is the fullest realization of the utopia, which that experience projected and was engendered after years of maturation.

Keywords: Oficina, Uzyna Uzona, Choir, Gracias Señor, Revolution.

Em 2004, convidado a participar de um colóquio na Pontifícia Universidade Católica do Rio de Janeiro (PUC-RJ), apresentei, atendendo ao tema do encontro que celebrava uma década da Cátedra Padre Vieira daquela instituição, o texto Dez anos de Usina Uzona e trinta anos do exilio português, posteriormente publicado'. Nele, propus o exame de uma década

1 Ver: RAMOS, 2005. 
do Uzyna Uzona - como o Teatro Oficina se autodenominou a partir de 1994 -, no momento de sua reinauguração no espaço planejado por Lina Bo Bardi; mas remeti, também, a 1974, ano em que o grupo partiu para Portugal e se engajou no processo da revolução portuguesa de 25 de abril. De fato, esta remissão visava retornar a 1971 e resgatar o papel seminal que o dito "trabalho novo" (ou o famoso Gracias, señor), à época, teve na evolução da companhia. Sobretudo, destacava a participação crescente do coro, importante desde Roda viva (1968), mas radicalizada em Gracias, señor e consolidada no futuro e já consagrado Uzyna Uzona de 2004. Apontava, também, a importância da revolução portuguesa na trajetória do grupo e no processo de radicalização existencial e política que culminaria na interrupção daquele ciclo criativo e, consequentemente, numa diáspora do Oficina. Desde o final dos anos 1960, - Oficina experimentava a transformação de uma companhia profissional com atores empreendedores em um coletivo em que, se não fosse abandonada a presença de protagonistas, tornava-se incontornável que eles contracenassem de forma decisiva com o coro, modificando radicalmente seus procedimentos construtivos e critérios de excelência anteriores. Essa radicalização estética e política do Oficina, cristalizada na hegemonia do coro, iniciada no Brasil em 1971 e germinada na revolução dos cravos, revela-se hoje, 50 anos depois e neste Brasil agônico do presente pandemônio geral, ainda vigorosa e vicejante. O coro "comeu" o velho Oficina e veio se refastelando nas três décadas do Uzyna Uzona.

Tudo começou em 1968, com Roda viva. A montagem contou com a participação de jovens atores sem nenhuma experiência profissional anterior: alunos da Escola de Teatro Martins Pena, no Rio de Janeiro, que passaram, já nomeados como coro, a integrar o Oficina. $O$ espetáculo confirmou a companhia como a mais ativa e criativa da cena brasileira ao mesmo tempo em que atraiu a fúria de grupos extremistas de direita que, por duas vezes, em Porto Alegre e em São Paulo, invadiram teatros para agredir os atores. Ainda em 1968, com uma participação ainda maior do coro, o Oficina estreou Galileu Galilei de Brecht, consolidando a apropriação transgressiva dos procedimentos épicos e a carnavalização de sua estética.

A estreia coincidiu com a promulgação do ato institucional $\mathrm{n}^{\circ} 5$ (Al-5) do Governo Militar, que restringiu as liberdades democráticas, endureceu a 
censura teatral e agravou a crise do Estado de direito. A esquerda brasileira dividiu-se entre duas estratégias: uma de combate à ditadura ainda de oposição política, e outra que abraçava a luta armada. O Oficina também refletirá essa divisão com um racha entre os atores mais antigos e estabelecidos da companhia e o cada vez mais forte coro, que tinha posições radicais não só nas questões políticas, como também nas existenciais, defendendo o uso de ácido lisérgico no processo de criação e a perspectiva de uma vida comunitária e antiburguesa. Esse racha é explicitado já em 1969, com o espetáculo Na selva das cidades, em que o jovem Brecht era encenado em um ringue de boxe onde, metaforicamente, enfrentavam-se "os personagens dos anos 1960" e os "coros dilacerados", e que já se prefigurava a revolução que estava por vir: no fim do espetáculo o próprio ringue era destruído. Já na montagem de Galileu Galilei, a tensão entre os atores "profissionais" e o coro, que era responsável pela cena do "carnaval do povo", tinha se elevado. Os atores "profissionais" dispunham de uma técnica, um ritmo e uma prontidão diferentes daquelas dos elementos do coro, com pouca prática e muito entusiasmo, ofereciam.

No início, parecia uma insanidade que o Oficina, no auge do seu status como o grupo de teatro brasileiro mais importante da época, não cultivasse esse prestígio e passasse a investir numa revolução interna. A dinâmica revolucionária, porém, não é movida à sensatez. Começaram a se definir as primeiras defecções dos atores históricos do grupo, que ali estavam desde a fundação. Zé Celso, cada vez mais, tomava o partido do coro e incentivava a radicalização que ele promovia. Ao mesmo tempo, a Companhia continuava funcionando em termos profissionais e precisava faturar para se manter. Em 1970, sob pesada repressão da ditadura militar, o Oficina "no paredão", como se definia, excursionou pelo Brasil com remontagens de $O$ rei da vela, Pequenos burgueses e Galileu Galilei. Nessa viagem, em que era preparado um novo espetáculo - provisoriamente chamado de "trabalho novo" acirraram-se as disputas entre os "atores profissionais" e o "coro".

A prática dos elementos do coro, de entrar em cena sob o efeito de ácido lisérgico, abria espaço nas apresentações para situações inesperadas, não raro problematizando o ato de contracenar com os colegas mais experientes. A soma desse esforço ainda profissional, que foi, inclusive, financeiramente bem sucedido, aos ensaios nas horas vagas do "trabalho novo", 
gerou o espetáculo de superação definitiva da fase anterior: Gracias, señor. Estreado em 15 de maio de 1971, em Brasília, o novo trabalho do Oficina foi apresentado para um público de 5 mil pessoas que acompanharam, no campus da Universidade de Brasília (UnB), os atores desenvolverem o que já não se pretendia mais ser um espetáculo teatral, mas, sim, um vero rito de passagem. Havia um roteiro prévio, mas, no rito em que se projetava a esquizofrenia coletiva e o processo de lobotomização ${ }^{2}$ em curso na sociedade brasileira, a apresentação já se estava mais próxima do conceito de happening e de performance - em que a relação com o público era intensificada e uma grande margem da encenação era deixada ao acaso. O teatro, ali, já era "te-ato", como o grupo passou a difundir.

Naquele mesmo ano, Gracias, señor ainda seria apresentado em Goiânia e Salvador, para grupos políticos na clandestinidade, e ensejaria uma vivência de trabalho comunitário com a população de Mandassaia, uma pequena cidade do sertão pernambucano. Em 1972, Gracias, señor chegou aos teatros, fazendo uma curta temporada no Rio de Janeiro e, finalmente, depois de 12 apresentações em São Paulo, foi proibido pela polícia. Naquela altura, o grupo original já tinha se modificado bastante e mesmo os atores protagonistas da primeira fase já atuavam como coro. $O$ coro se tornou hegemônico e o próprio diretor, Zé Celso, deslocou-se à condição de ator participante.

O texto, ou roteiro, de Gracias, señor, é um dos registros possíveis para analisá-lo (há um registro fílmico guardado na Cinemateca Brasileira) e revela uma estrutura mais rigorosa do que se poderia supor em circunstâncias de criação tão abertas. Na verdade, é uma colagem de textos de Nietzsche (Assim falou Zaratustra), Shakespeare (Hamlet), Brecht (Mahagonny) e Oswald de Andrade (Manifesto antropofágico e Serafim ponte grande) estruturados num jogo dramático simples e direto. Anunciava-se que o teatro morrera e que não haveria por que estar ali, representando para um público pequeno-burguês. A solução apresentada a tal impasse era reconhecer a morte em vida e projetar a necessidade de superação de uma identidade falsa,

2 A lobotomia é uma técnica terapêutica para casos graves de esquizofrenia, hoje superada, desenvolvida em 1935 pelo médico neurologista português Antônio Egas Moniz (1874-1955). Ela implica cirurgia no cérebro seccionando as vias que ligam os lobos frontais ao tálamo e a outras vias frontais associadas. Moniz recebeu o prémio Nobel de Medicina em 1949 pela "descoberta". 
calcada no conformismo e geradora de um "homo normalis", que se contrapunha à necessidade de que se assumisse uma esquizofrenia incontornável, o que, por sua vez, permitiria alguma espécie de superação. Há, aqui, uma inevitável redução e simplificação, já que o espetáculo era apresentado em 12 horas, durante duas noites, e muitos dos que assistiram narram ter sido uma experiência única e inigualável - como algo que evocava a utopia de Antonin Artaud de um teatro que reinventasse a vida -, além de responder às influências diretas do The Living Theatre, de Julian Beck e Judith Malina, que estiveram seis meses convivendo com o grupo Oficina em 1970.

De qualquer modo, para efeito do que se pretende aqui que é projetar esse espetáculo não como o fim do Oficina, como fez a historiografia oficial, mas como o início de uma fase que passa pela revolução portuguesa e firma as fundações do Uzyna Uzona e das realizações dos últimos decênios, bastam esses dados.

Retornando a 1972, impedido de continuar com Gracias, señor, o Oficina ainda tenta montar As três irmãs, de Anton Tchekhov, no final daquele ano. Seria a última tentativa de mesclar os atores profissionais do núcleo inicial com os que tinham permanecido do coro de Roda viva. A montagem chega a viajar pelo Brasil, mas o Oficina não resiste às contradições internas e os últimos remanescentes do grupo fundador, particularmente Renato Borghi, o ator mais importante da fase anterior, se retiram. Em 1973, o grupo muda de nome, tornando-se Comunidade Oficina Samba, em que "Samba" significa Sociedade Amigos Brasil Animações. Em abril de 1974, no auge da repressão à guerrilha urbana, o teatro foi invadido pela polícia, que leva José Celso preso. Convidados a se retirarem do país, o diretor e os integrantes do Oficina Samba seguem para Portugal.

\section{O Oficina Samba na revolução dos cravos: ensaio para um renascimento}

Em Lisboa, chegando em plena efervescência revolucionária, o Oficina foi recebido cordialmente pelos jovens oficiais portugueses - afinal, seus integrantes tinham combatido ao lado da esquerda brasileira e a revolução precisava de agentes culturais. O grupo foi instalado em um casarão que pertencera 
à Juventude Salazarista e passou a viver como uma verdadeira comunidade alternativa. Desde a alimentação macrobiótica e a massagem oriental, até o regime permanente de estados alterados de consciência, com vinho, haxixe ou química, criava-se um contraponto de radicalização comportamental e cultural às transformações políticas que ocorriam na sociedade portuguesa.

A história desse período não está oficialmente escrita e, por conta das implicações políticas e de segurança, foi mantida em sigilo por décadas. Há 30 anos, dois participantes do grupo que viveram a experiência portuguesa do Oficina, Joel Cardoso de Oliveira e Luiz Fernando Guimarães, gravaram uma conversa em que, perguntados por interlocutores, evocaram aquele período. Guimarães foi uma figura chave no confronto entre o coro e os protagonistas por ter sido administrador da companhia em toda a fase descrita, além de ser um dos autores do roteiro final de Gracias, señor e ator em diversas montagens; Oliveira, por sua vez, era um ator que tinha sido atraído para o grupo por Gracias, señor. De uma certa maneira, a visão que trazem do Oficina representa essa visão do coro, que nunca foi exatamente considerada pelos historiadores e sempre apontada como uma deturpação das raízes originais. Pode-se dizer, emprestando as palavras de Guimarães, que em Portugal "o coro come", significando não só a afirmação do direito de comer de atores que não tinham as mesmas condições salariais dos mais antigos, como a tensão política interna e a devoração do próprio Oficina. É desse depoimento ${ }^{3}$, que mereceria ser publicado na íntegra, que empresto alguns episódios sobre a participação do Oficina na revolução dos cravos.

Em 31 de dezembro de 1974, os 16 integrantes do Oficina Samba que estavam em Portugal - e aos quais se agregariam, na convivência, atores portugueses, moçambicanos e cabo verdianos - apresentaram uma versão de Galileu Galilei para um único espectador: tratava-se de Márcio Moreira Alves, o político brasileiro cujo discurso na Câmara Federal, em Brasília, em dezembro de 1968, servira de estopim para o já citado Ato Institucional no 5 . Como diz Guimarães em seu depoimento,

dezesseis caras que nós éramos, fazendo uma noite, quatro ou cinco horas, um espetáculo cansativo dentro de uma casa, só para Marcito.

3 Texto datilografado acessado numa única oportunidade e nunca publicado. 
Esse tipo de apresentação repetiu-se ene vezes em ene lugares do mundo. Isso não era teatro, isso podia ser um ensaio, isso podia ser qualquer coisa, mas não numa noite de ano novo, a gente passar quatro ou cinco horas fazendo um espetáculo só para o Marcito.

O mesmo Galileu Galilei, fosse na versão integral, fosse em partes, principalmente o chamado "Carnaval do Povo", foi apresentado centenas de vezes em Portugal nas mais diversas circunstâncias. Uma delas foi para o Conselho da Revolução, que assistiu ao espetáculo no Teatro São Luiz para liberá-lo ao público. Depois, foi feita uma temporada naquele mesmo teatro, além de dezenas de apresentações de rua. Nesses casos, o grupo apresentava ora algum trecho do espetáculo como teatro de rua, ora interagia com as manifestações de rua da revolução - que, naquele período, parece, ocorriam diariamente utilizando elementos do espetáculo ou improvisando. Houve também viagens por Portugal, para a região de Coimbra, onde fizeram algumas apresentações.

Em São João dos Campos, ocorreu um episódio menor que ganhou muita importância, e merece ser mencionado como exemplar das circunstâncias paroxísticas que o Oficina Samba, em clima revolucionário, se viu metido: numa apresentação de Galileu Galilei para pescadores, que os relatos comprovam ter sido uma das mais felizes e precisas das que o grupo realizou em Portugal, uma das atrizes tropeçou sobre um pescador. Talvez porque a atriz estivesse alcoolizada, aquilo foi lido pelas más línguas como assédio e logo a esquerda brasileira estaria cobrando mais compostura.

A verdade é que, independentemente de detalhes e fofocas, havia um racha estabelecido no teatro de esquerda entre uma linha de leitura de Brecht, representada pelo Teatro de Arena, e a que o Oficina abraçava ao fazer Galileu Galilei. Os últimos integrantes que prezavam a racionalidade de um Brecht sisudo e cerebral já tinham partido. Imersos na viagem da ampliação de consciência e soltos na revolução, o grupo arrepiava os cabelos de muita gente.

Nessa toada, simultaneamente de radicalização e de dispersão, a unidade do grupo foi se esgarçando e, por volta de julho de 1975, aquele Oficina estava a ponto de se estilhaçar - e foi o que aconteceu. Zé Celso partiu para Moçambique para filmar Vinte e cinco, iniciando uma década que seria dedicada ao cinema. Jean Luc Godard tinha estado em Moçambique, apresentando o cinema aos moçambicanos, e Zé Celso foi seguir essa trilha. 
Guimarães ficou em Portugal mais um ano, trabalhando com o LUAR, grupo de militares radicais que coordenava ocupações. Dos demais integrantes, alguns se espalharam pela Europa e outros retornaram ao Brasil, como foi o caso de Maria Alice Vergueiro.

O que se pode dizer de toda essa experiência é que aquele grupo que vinha testando seus limites no processo político e cultural brasileiro, encabeçando o Tropicalismo no teatro e aliando-se à luta armada no plano político, encontrou, no contexto revolucionário português, um ambiente ao mesmo tempo atrativo e destrutivo. Permitiu que a radicalização existencial e política se aprofundasse, exaurindo a coesão e as potências artísticas, fazendo cumprir-se o fim daquele ciclo. Nesse sentido (e isso é o que importa destacar aqui), nada poderia ser como antes quando, a partir de 1978, José Celso voltou ao Brasil e retomou a prática teatral - enfrentando, de imediato, a difícil tarefa de demolir o antigo teatro Oficina e reconstruí-lo com um novo projeto: o da Uzyna Uzona, "terreiro eletrônico" no formato de rua, ou pista, e incorporando tecnologias cinemáticas.

A hipótese é que, nos dez anos seguintes, que foram de concepção e gestação de um novo ciclo criativo, a hegemonia do coro, consolidada e expandida na revolução portuguesa, tornou-se o principal esteio e uma verdadeira bússola. Nas três últimas décadas, que engendram e consagram o Uzyna Uzona e o conciliam com o nome Oficina, Zé Celso nunca abandonou o coro como procedimento básico de criação e eixo mais relevante nos processos de criação. Assumido como aquele que come - ou devora, na perspectiva da antropofagia de Oswald de Andrade - tudo que vier pela frente, o coro venceu.

Quando retornou à cena, no caminho para chegar ao atual te(a)tro, Zé Celso continuou priorizando o trabalho com o coro. Em todas suas encenações posteriores à reconstrução do espaço com a atual arquitetura, manteve a centralidade e a hegemonia do coletivo. Se continuou contando, nessas muitas novas montagens com atores e atrizes convidados a papéis protagonistas, em todas elas, teve o coro como pivô estruturante, em torno do qual se construíram a dramaturgia e a música. Quase sempre era notável como o protagonismo dos convidados acabava sendo compartilhado por artistas daquele coletivo, que cada vez mais se destacavam. De fato, o coro não é um corpo estável e homogêneo, que foi sempre o mesmo desde 1994; é sim um 
grupo sempre em transição, na maior parte das vezes integrado por jovens atrizes e atores iniciantes, de preferência que não tenham passado pelas escolas de teatro e adquirido vícios de formação, mas também aberto a esses. Curiosamente foi, também, a partir do coro que emergiram os novos protagonistas da companhia - nomes como Camila Motta e Sylvia Prado, entre tantos que por lá passaram nessas últimas décadas, muitos dos quais fizeram da experiência seu processo de formação, tendo hoje carreiras independentes.

De uma certa forma, a monumental realização dessa última fase, da reinauguração até hoje, se nunca deixou de ter a presença de Zé Celso como guia, teve seu verdadeiro dínamo nessa energia despersonalizada, mas sempre vitalíssima, do coro. Na verdade, em todas as encenações, Zé Celso operou sempre muito mais como Corifeu, regente do coro, do que como protagonista.

Nessa perspectiva, a ampliação do espaço de representação para além dos limites da pista/terreiro, o verdadeiro "palco" do Uzyna Uzona passou também a não envolver mais apenas os integrantes do grupo, mas a enlaçar o público (como sonhavam os criadores de Gracias, señor) num verdadeiro movimento de "atar" como participantes todos os presentes. O convite à interação com os atores tornou-se a marca dos espetáculos do Oficina nos últimos 27 anos, que passaram a efetivar a comunhão que não fora possível em 1971. Por exemplo: em várias cenas dos cinco espetáculos da monumental adaptação de Os sertões, o público acostumou-se a invadir o espaço central do teatro e lá permanecer demoradamente como atuante. $O$ mesmo fenômeno se deu na Alemanha, no Festival Internacional de Teatro do Vale do Rühr, quando foi apresentada a primeira encenação integral do ciclo, incluindo-se $A$ terra, O homem e uma primeira versão da $A$ luta, ao longo de vários dias - já que cada espetáculo tinha em média 5 horas. O público alemão rendeu-se aos encantos dos espetáculos e interagiu fortemente em algumas cenas. Essa poderia ser considerada uma prova definitiva do ponto que se quis, aqui, defender. $\mathrm{O}$ atual teatro Oficina Uzyna Uzona é a realização acabada da utopia que Gracias, señor projetou e que décadas de maturação conseguiram engendrar.

É claro que há de considerar, também, em toda essa especulação, como José Celso Martinez Corrêa manteve-se em um lugar central, solar, durante todo o processo. Ele foi o que, por décadas, carregou a aura do grupo original, e que hoje se vê na situação, inegavelmente conquistada, de "anarquista coroado". 
Esse tema, entretanto, extrapola os limites da reflexão proposta. Basta apontar como a estratégia adotada baseou-se em um programa gerado no núcleo do coro, no processo de encenação do Roda viva e que, bem irrigado e sustentado nesses últimos 30 anos por vários coros, em várias levas de jovens artistas, foi ele próprio plenamente coroado.

\section{Referências bibliográficas}

RAMOS, L. F. Dez anos de Usina Uzona e trinta anos do exílio português. In: MARGATO, I.; GOMES, R. C. (org.). Literatura, política e cultura (1994-2004). Belo Horizonte: Editora UFMG, 2005. p. 269-279.

Autor convidado 
